\title{
Focus sensitivity in Hungarian adults and children
}

\author{
Bence Kas \\ Research Institute for Linguistics, Hungarian \\ Academy of Sciences; \\ Bárczi Gusztáv Faculty of Special Pedagogy, Eötvös \\ Loránd University, Budapest \\ kas.bence@nytud.mta.hu \\ Ágnes Lukács \\ Department of Cognitive Science, Budapest \\ University of Technology and Economics \\ alukacs@cogsci.bme.hu
}

\begin{abstract}
Focus sentences in Hungarian are claimed to express exhaustive identification by a syntactic-semantic operator in standard generative descriptions, but there are also arguments against this view. Our study aimed to gather empirical evidence for the exhaustive interpretation of focus sentences and to explore developmental changes with age. Two groups of children (mean ages 6;3 and 10;8 years) and a group of adults participated in a picture-sentence verification task that systematically varied sentence and context types. Adults showed a marked sensitivity for focus as a group, but focus sensitivity was not evident in either group of children. All participant groups were remarkably inconsistent in distinguishing neutral and focus sentences. In spite of the measurable sensitivity to focus in adults, the pattern of the results contradicts the predictions of the syntactic-semantic operator model concerning exhaustive interpretation, and urges further research.
\end{abstract}

Keywords: focus; exhaustivity; comprehension; language development; syntax

\section{Introduction}

\subsection{Theoretical models of focus interpretation}

In natural languages, there are several kinds of structures that express set relations or operations on elements of a set, such as universal or existential quantification, exclusion, etc. Most of these functions are lexically specified (e.g., the particles every and only in English), but in some languages, like Hungarian, such set operations can be expressed through syntactic-prosodic cues alone, as illustrated by examples in (1a-b). Although these sentences only differ in their word order and prosody, Hungarian speakers tend to interpret (1b) but not (1a) exhaustively, that is, they 
interpret the predicate as being true only for the subject (focus is marked by capital letters throughout the paper).

(1) a. Sári fel hívta Pétert.

Sári up call-PST-3SG Peter-ACC

'Sarah called Peter.'

b. SÁRI hívta fel Pétert.

Sári call-PST-3SG up Peter-ACC

'It was Sarah who called Peter.'

Generative descriptions explain this phenomenon by specific semantic operators associated with certain syntactic structures. While in (1a) the subject Sári is in topic position, in (1b) it occupies the position directly preceding the verb, bearing contrastive stress (causing the verbal prefix fel to appear in the post-verbal position). This constituent is referred to as the focused one, according to É. Kiss (2008b, 5): "The focus is an immediately preverbal constituent, expressing exhaustive identification, bearing a pitch accent". Although there are several technical elaborations in the literature, linguists adopting the generative framework follow the principles of Chomsky (1971) and agree that the exhaustive interpretation of preverbal focus is specified at the semantic level, that is, exhaustivity is part of the truth conditions of focus sentences so that the predicate is true only for the focused constituent, and for no other (Szabolcsi 1981; Farkas 1986; É. Kiss 1998; 2002; Brody 1990; 1995; Kenesei 2005; 2006; 2009). These authors distinguish preverbal (identificational) focus from what is called information focus, which is marked only prosodically and does not occur preverbally hence does not express exhaustive identification, such as B's answer in (2).

(2) A: Kit hívtál fel?

who-ACC call-PST-2SG up

'Who did you call?'

B: Fel hívtam például JÁNOST.

up call-PST-1sG for-example János-ACC

'I called John, for example.'

In this view, exhaustivity as a semantic feature is associated with preverbal focus as a syntactic-prosodic structure. To summarize this proposal, there are two kinds of foci: informational and identificational, and only the latter is claimed to involve a logical-semantic operator. 
However, Kálmán and van Leusen (1993) take a different position and make a distinction between bound and free focus. Bound foci occur in the scope of a logical operator like the adverbial only and are associated to that semantically. Free foci without adverbs are not specified lexically and do not correspond to semantic operators. In contrast, sentences with free focus presuppose an exhaustive context, in which a certain predicate is true for one and only entity. Kálmán and van Leusen (1993) claim that sentences with free focus are appropriate only in such contexts, as revealed by counterexamples with non-exhaustive prelude (3).

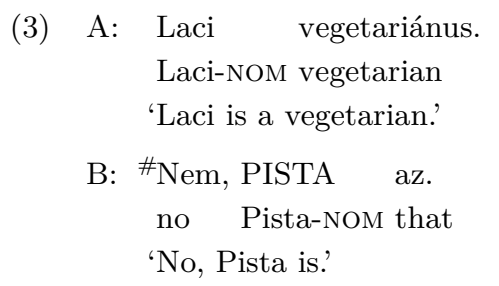

According to Kálmán and van Leusen (1993), free focus does not express exhaustivity; exhaustivity is a property of certain contexts that permit the occurrence of focus sentences. A focus sentence claims an identificational statement to a state of affairs that follows from the context. The main point is that focus sentences presuppose that the state of affairs specified by the context is exhaustive, instead of claiming it. Accordingly, the best paraphrases of focus sentences like (4a) are sentences with a relative clause such as (4b). The focus sentence (4a) identifies János as the only consumer of the soup by presupposing that there was a single person eating the soup and claiming that it was János.

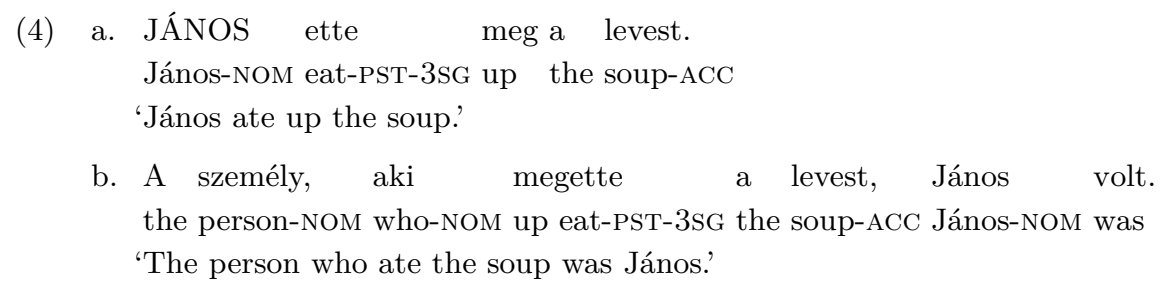

Recently, several different approaches argue against either the syntactic-semantic operator view of preverbal focus or exhaustivity being related to focus in semantic terms on different grounds (É. Kiss 2006a; 2008b; 2011; Szendrői 2003; 2004; Wedgwood 2003; 2005; Onea 2009; for a critical discussion, see É. Kiss 2006b). 
In her more recent papers, É. Kiss (2006a; 2008b; 2011) suggests a reformulation of the generative theory of focus rejecting the operator view. She argues that preverbal focus should be analysed as a specificational predicate that specifies the referential content of the background proposition, thereby presupposing the existence of it at the same time. This analysis is much more elaborated in syntactic terms than Kálmán and van Leusen's (1993), yet it results in a somewhat similar view of the semantics of focus. The essential difference between these views is whether the exhaustivity of focus is claimed or presupposed. The essential difference between these views is whether the exhaustivity of focus is implied or presupposed. According to É. Kiss (2006a), the exhaustive interpretation of focus is the consequence of its specificational role. As the specificational predicate identifies the particular referents that the sentence is claimed to be true for, it is implied that the list of these referents is exhaustive. In contrast, Kálmán and van Leusen (1993) suggests that exhaustivity is a property of the set of referents determined by the context, so exhaustivity is presupposed instead of being claimed by the focus.

Szendröi $(2003 ; 2004)$ claims that the analysis of focus as a syntactic-semantic operator is not well-motivated. Based on the principles of Reinhart (1995) and Selkirk (1984), she suggests that semantic focus corresponds to prosodic focus and that the syntactic focus feature is unnecessary to account for the data (Szendrői 2003; 2004). She argues that, since the main stress falls on the verb or its modifier in Hungarian neutral sentences, the reason for the positing of preverbal position of focus is that we move the highlighted constituent to the main stress position. On this view, focus is determined by prosodic features instead of syntactic ones, and syntactic position is merely a consequence of the prosodic structure of the language. Szendröi (2003) argues against the dichotomy between identificational and informational foci based on intonational and pragmatic arguments, but, admittedly, her theory is unable to explain why preverbal focus is interpreted exhaustively contrary to postverbal focus.

According to Wedgwood (2003), it is unnecessary to assume exhaustivity as being a semantic feature associated with the syntactic structure. Referring to the relevance principle of Sperber \& Wilson (1995), he proposes that exhaustive interpretation is the optimally relevant reading in natural communicative situations, as we take it for granted that the speaker does not hold back relevant information. Therefore, exhaustive interpretation is plausible even for sentences without focus. Wedgwood (2003) cites English examples to show that sentences with only prosodic focus are interpreted exhaustively in certain situations. This position is 
supported by well-known observations: neutral sentences are generally interpreted exhaustively depending on the context. Requesting a cup of coffee is just as possible with a sentence with (5a) or without (5b) focus, both of which are naturally understood as it is only a cup of coffee and nothing else that we asked for. The reason for this is that the listener assumes that we would not hold back relevant information, that is, that there is something else we would also like to have.

(5) a. Egy KÁVÉT kérek!

a coffee-ACC ask-PRS-1SG

'A coffee, please!'

b. Kérek egy kávét!

ask-PRS-1SG a coffee-ACC

'A coffee, please!'

Wedgwood's (2003; 2005) arguments do not refute the semantic determination of exhaustive interpretation and its association with syntactic structures, they only suggest that these are unnecessary. However, Wedgwood et al. (2006) cite corpus examples that make the semantic feature theory of exhaustive interpretation very difficult to hold. Preverbal focus together with a non-exhaustive adverb should result in a semantically illformed sentence, which is definitely not the case in (6) taken from Onea \& Beaver (2011).

(6) Péter többek közt MARIT csókolta meg.

Péter-NOM among others Mary-ACC kiss-PST-3SG PRT

'Peter kissed Mary, among others.'

Wedgwood's argumentation is developed further by Onea $(2007 ; 2009)$ and Onea and Beaver (2011), who argue that the exhaustive interpretation of preverbal focus is explained by pragmatic principles. Their basic assumptions are that preverbal focus is the specific syntactic structure to use in answers and that the responses given to questions are generally taken as exhaustive. Although they do not cite Kálmán and van Leusen (1993), they describe the problem of exhaustivity explicitly as being a debate between semantic entailment, presupposition and implicature. According to Onea $(2009,59)$, the main difference between the semantic and pragmatic theories is that "exhaustive interpretation may be facilitated (pragmatic) but not determined (semantic) by the linguistic form". In our view, the difference between the presupposition theory (Kálmán and van Leusen, 1993) and the pragmatic implicature hypothesis (Onea 2007; 2009; Onea 
\& Beaver 2011) is the following. The former claims that focus sentences are appropriate only in exhaustive contexts, since focusing presupposes an exhaustive context. When this presupposition is not satisfied, a focus sentence might sound odd and its truth value is difficult to judge. This does not follow from the implicature hypothesis as it claims that exhaustive interpretation emerges from both the sentence and its context, emphasizing the latter. This is exemplified by (quite frequent) cases where listeners interpret neutral sentences exhaustively assuming that the speaker would not hold back relevant information, as for example in (5b). Onea (2009) also takes into account grammatical features such as aspect, and claims that verbal prefixes are important for the exhaustive interpretation of focus sentences: sentences with a prefix are interpreted exhaustively more often than those without a prefix. He argues that verbal prefixes generally mark aspect (perfectivity being the most frequent), and that perfective verbal prefixes contribute to a stronger tendency for exhaustive interpretation.

However, all the arguments presented above are based on introspective analyses, i.e., the acceptability/grammaticality of the example sentences is judged by the linguists themselves. Our main aims here are (1) to explore whether exhaustive interpretation of Hungarian focus sentences is evidenced in a controlled experiment with adults and children, and (2) to study the patterns of how different grammatical structures and contexts affect interpretation. Below we first review the literature on the processing of focus sentences, then present new results from our experiment.

\subsection{Focus effects in sentence processing}

Several studies showed that focusing influences adult sentence processing. Prosodic stress enhances sentence comprehension (Birch \& Clifton 1995; Bock \& Mazzella 1983) and focused information is easier to perceive and remember than non-focused information (Cutler \& Fodor 1979; Pléh \& Sinkovics 2011; Malt 1985). Pléh and Sinkovics (2011) also show in a listening task that adults generally fail to remember the word order of neutral sentences 16 seconds after presentation, while they remember word order in sentences with marked information structure, that is, focus, even 40 seconds after presentation. They take this result to show that the information structure mediated by focusing is stored in long term memory. Filik et al. (2009) studied eye movements during reading and showed that in focus sentences with the particle only, constituents which follow the focused phrase but are semantically inconsistent with it are associated with significantly more regressive saccads. The authors argue that this pattern is indicative 
of the early computation of the set contrast (that is, the ongoing exclusion of other possible referents of the relevant set). Many studies investigated phenomena such as the effects of focusing on the comprehension of relative clauses (Paterson et al. 1999; Liversedge et al. 2002), on the resolution of syntactic ambiguities (Filik et al. 2009); these experiments also support the facilitating effect of focus on information processing. In an earlier study of Hungarian adults, Gergely $(1988 ; 1991)$ investigated how previous clausal context affects the recognition times of words presented right before the clause boundary in a cross-modal priming experiment. He found inter alia that the auditory presentation of an initial main clause with a contrastively focused object (e.g., plates) facilitates the visual recognition of words related to the input state of objects (e.g., dirty) in the event determined by the verb (e.g., washing). Gergely concludes that pragmatic knowledge is accessed directly and early by the online interpretational mechanisms and that these focus-based inferences can be clearly distinguished from lexical associative effects owing to their different time course. Thus, it seems that effects of focusing are evident in empirical studies and that inferences about sentence meaning based on focused constituents are made quite early in online sentence processing.

There are also developmental studies from several languages on the age-related changes in the comprehension of lexically specified focus, that is, on sentences with exhaustive adverbs. These studies show that children under ten years interpret focus sentences differently from adults. There is also evidence that children between 3-6 years produce particular errors in the identification of the scope of the particle only. For example, there seems to be an asymmetry in the comprehension of sentences with direct or indirect object in focus in both English and Portuguese. Sentences with the clause-final indirect object in focus such as The farmer only sold a banana to Snow White are understood by children between 4-5 years at an adult level in a truth value judgment task (Crain \& Thornton 1998). In contrast, sentences with direct object focus marked with contrastive stress such as The farmer only sold a BANANA to Snow White are interpreted like sentences with indirect object focus by most children (Gualmini et al. 2003; Costa \& Szendrői 2006).

Another age difference in the interpretation of scope was pointed out by Crain et al. (1994) and Philip and Lynch (2000) in the comprehension of subject NP focus and VP focus. Children interpreted sentences such as Only the cat is holding a flag as VP focus instead of narrow subject NP focus (it was the cat who held a flag), similarly to real VP focus sentences such as The cat is only holding a flag. However, there is an ongoing 
debate whether this pattern is caused by ignoring syntactic information or by immature interpretation of set relations. Crain et al. (1994) argue that children do not pay attention to the surface position of only, that is, they do not use the available syntactic information. Paterson et al. $(2005 / 2006)$, however, claim that children simply do not calculate alternative sets, but represent the content of the sentence without only which results in a wider interpretation. Paterson and colleagues studied children between $6-7,8-10$ and 11-12 years and adults comparing truth value judgments for sentences with subject focus, VP focus and without only in the context of six types of pictures. Their results showed that children's performance on subject focus sentences approaches adults' performance gradually (children between 6-7 and 8-10 years were significantly below adults in subject focus sentences but children between 11-12 years were similar to them). Children between 6-7 years showed some evidence of having difficulties with the computation of alternatives in the discourse by generally accepting both subject $\mathrm{NP}$ and VP focus sentences such as The fireman is only holding a hose and Only the fireman is holding a hose for pictures with the fireman holding a ladder and a hose (VP contrast) and a policeman holding another hose (subject contrast) next to him. This pattern is not predicted by the syntactic hypothesis of Crain et al. (1994). Children in the Paterson et al. (2005/2006) study produced more errors owing to neglecting contextual contrast information than to scope misinterpretation.

The results of Crain et al. (1994) were replicated with 4-year-old children speaking Mandarin Chinese by Notley et al. (2009) and Zhou and Crain (2010). Although Chinese adults interpreted sentences with the particle zhiyou 'only' preceding the subject as subject focus sentences, children interpreted the same structures as VP focus sentences. However, when discourse context was modified to direct children's attention to one of the participants of the stimulus story by questions before and after the presentation of the story, most children produced responses similar to adults', that is, they showed evidence of subject focus interpretation. According to Zhou and Crain (2010), this pattern proves that children are able to compute relevant discourse sets, so the reason of their general tendency for VP focus interpretation must be of grammatical origin. An alternative interpretation of these results is that children are indeed able to use contextual information appropriately when they are guided to do so, yet they apply a simpler and less specific strategy by default.

Turning to Hungarian, corpus studies revealed that focusing emerges quite early in child language. Babarczy (2006) investigated the frequency of verbal prefixes occurring after the verb - a syntactic marker of focus - in 
the spontaneous speech corpus of 6 children between 1;8-2;11 years. She showed that the occurrence of verbal prefixes outside the preverbal position shows gradual increase with age but is already present even in the earliest samples in so-called focusable contexts (that is, in environments where prefixes can occur either before or after the verb and where focusing is not obligatory because of other linguistic factors such as negation or question words; see table 1).

Table 1: Ratio of verb-prefix sequences in focusable contexts by age groups based on Babarczy (2006)

\begin{tabular}{lc}
\hline Age & Ratio of verb-prefix sequences \\
\hline $1 ; 8-2 ; 2(n=6)$ & $6 \%$ \\
$2 ; 3-2 ; 7(n=6)$ & $8 \%$ \\
$2 ; 8-2 ; 11(n=6)$ & $15 \%$ \\
Adult $(n=1)$ & $23 \%$ \\
\hline
\end{tabular}

Note that the data in table 1 only shows children's use of focus sentences: neither the presence of csak 'only' nor the grammaticality of these structures are documented. Earlier observations suggest that small children begin marking focus prosodically by stress earlier than by placing verbal prefixes in non-preverbal position (Pléh 1998). The case studies of two children by Tóth (2008) go further in this respect. She identified focus sentences by contextual information and investigated the frequency of both grammatical and ungrammatical sequences of verb and prefix. Her results replicate Babarczy's (2006) findings in that focus sentences are already present in the spontaneous speech of two-year-olds. Tóth (2008) also shows that the proportion of sentences with prosodic focus where the verbal prefix stays before the verb (exemplified in (7)) is gradually decreasing between $2 ; 0-2 ; 7$ years.

(7) A NAGYOT megeszem.

the big-ACC PRT eat-PRS.1SG

'I eat the big one.'

In Tóth's (2008) account, the adult-like marking of focus by joint syntactic and prosodic markers becomes stable at around 3;0 years of age.

As far as we are aware, the only empirical study that investigated the exhaustive interpretation of focus sentences in Hungarian is by Onea and Beaver (Onea 2009; Onea \& Beaver 2011). Adult participants were shown 
pictures depicting non-exhaustive events featuring two agents performing similar actions (e.g., both catching butterflies), and heard a sentence chosen from three types: neutral SVO, subject focus and subject focus with csak 'only'. All subjects in the sentences were singular nouns. Then participants had to verify the sentence-picture pair by choosing from three written response schemes: (1) Yes, and..., (2) Yes, but..., (3) No, ... with a supplement clause describing the action of the other agent seen in the picture. Onea and Beaver argued that given the two-agent context, subject focus sentences with csak 'only' are false, while neutral sentences are acceptable though pragmatically misleading. They predicted that focus sentences without csak 'only' would be rejected if they are semantically exhaustive, while they would be accepted like neutral sentences if exhaustivity is only implied pragmatically. Acceptance was defined as either (1) Yes, and..., or (2) Yes, but... responses. According to the results, participants accepted more subject focus sentences $(\sim 70 \%)$ than subject focus sentences with csak 'only' ( 15\%), but less than neutral sentences $(\sim 90 \%)$, and only the difference between the two focus structures was significant. Based on this finding, Onea and Beaver argue that the exhaustive interpretation of focus sentences is not semantically based. Their view is supported by the fact that half of the $70 \%$ of positive responses for subject focus sentences were of the (2) Yes, but... type suggesting that participants held these sentences true for pictures with two agents despite their need to add a reservation. However, it has to be noted that in the pictures, the two agents are always acting on different patients which are marked by NPs with an indefinite article, e.g., (8).

(8) MARCI fogott meg egy lepkét.

Marci-NOM catch-PST3SG PRT a butterfly-ACC

'It is Marci who has caught a butterfly.'

This momentum is important as it seems that subject focus sentences would be less acceptable if pictures showed two agents acting on the same patient, i.e., if, for example, they caught a single butterfly together. Moreover, the presence of sentences with csak 'only' in the experiment might lead to a meta-strategy biasing participants to the predicted results. As sentences with csak 'only' are clearly exhaustive, the lack of csak 'only' might result in a permissive bias for focus sentences in adults being sensitive to gradation. Results also showed that participants interpreted neutral sentences exhaustively to a similar degree as focus sentences, which is in concert with the authors' concepts. Note, however, that there were too few sentences in the experiment as participants heard only two tokens in each 
sentence type. This prevented the use of parametric statistics and makes the results too sensitive to individual variation. These concerns suggest caution in the evaluation of Onea and Beaver's results, and at the same time urges further research in this promising direction.

\subsection{Hypotheses}

There are three competing hypotheses in the literature attributing exhaustive interpretation of focus sentences to (i) a syntactic-semantic operator (Szabolcsi 1981; Farkas 1986; É. Kiss 1998; 2002; Kenesei 2005; 2006; 2009), (ii) semantic presupposition (Kálmán \& van Leusen 1993), and (iii) pragmatic implicature (Wedgwood 2003; 2005; Onea 2007; 2009; Onea \& Beaver 2011). In the study presented below, we do not aim to directly differentiate between them; we constructed the following experiment with only the traditional syntactic-semantic operator hypothesis in mind. Our main aims are (i) to gather empirical evidence for (or against) exhaustive interpretation of Hungarian focus sentences in a controlled experiment, (ii) to compare the effect of the different grammatical features marking focus (such as pre-verbal position, contrastive stress and postverbal position of verbal prefix) on exhaustivity, and (iii) to study the patterns of development with age, possibly showing the emergence of exhaustive interpretation. We used a sentence-picture verification task that enabled us to compare comprehension patterns for different sentence and context types. Based on the relevant theoretical and psycholinguistic literature discussed above, the following expectations can be formulated. Hypotheses 1-2 (below) are quite clearly predicted by the syntactic-semantic operator model, while hypotheses $3-4$ are rather questions than exact predictions motivated by the characteristics of the generative analysis of Hungarian syntax behind the syntactic-semantic operator model of focus. Hypotheses 5-6 are based upon previous psycholinguistic research presented above.

1. Adult speakers accept focus sentences as well as neutral sentences in exhaustive contexts.

2. Adult speakers do not accept focus sentences but do accept neutral sentences in non-exhaustive contexts. This pattern would reveal focus sensitivity.

3. Sensitivity for different focused constituents (e.g., subject versus object) does not differ. This hypothesis is motivated by the specific 
characteristics of Hungarian modelled in the formal generative framework behind the syntactic-semantic operator hypothesis of focus. É. Kiss (2008a) reviews arguments concerning subject-object hierarchy in Hungarian and claims that subjects and objects can occur in the same word order positions including topic and focus. The symmetry of focusability between subject and object in Hungarian was also supported by a cross-linguistic empirical study (Skopeteas \& Fanselow 2010). Thus, the syntactic-semantic operator model based on the generative framework does not predict any differences between subject and object focus sensitivity. However, there seems to be a frequency difference in subjects and objects occurring in preverbal position that might predict such a pattern. A corpus analysis based on a subset of the Hungarian National Corpus with the use of regular local grammars over part-of-speech tag sequences showed that the SOV pattern is the predominantly most frequent word order in Hungarian - more frequent than the other five possible variations together. ${ }^{1}$ This might imply that objects more naturally occur in preverbal position than subjects, so the recognition of object focus might be more difficult. In other words, a sentence with a preverbal subject is in bigger contrast to a non-focused subject and pops out more than one with a preverbal object just because it is more unusual. This could yield an asymmetry in focus sensitivity between subject and object focus sentences, a pattern that is predicted by theories concerned with language use and experience, but not yet motivated by formal generative models of Hungarian syntax.

4. Acceptance rates for focus sentences in non-exhaustive contexts might be comparable to those for other types of semantic anomalies such as referential mismatches between sentence and picture. In a strict reading of the syntactic-semantic operator model, exhaustivity is part of the truth conditions of focus sentences. Thus, a focus sentence referring to a non-exhaustive event must be judged false just as well as one with other kinds of semantic anomaly such as a referential mismatch. However, the specificational predicate analysis of É. Kiss (2006a; 2008b) and the presupposed exhaustivity hypothesis of Kálmán and van Leusen (1993) allow for a more sophisticated approach. In both views, the truth conditions of the propositional content and the identificational (focus) predicate might be separated,

${ }^{1}$ The authors are grateful to Csaba Oravecz for the results of his unpublished corpus analysis. 
so a violation of the latter does not necessarily result in a totally false sentence. The question is whether speakers treat semantic anomalies of the proposition and violations of the exhaustive predicate differently. If they do, then we might expect different acceptance (or rejection) rates for focus sentences in non-exhaustive contexts and semantic anomalies of the proposition such as referential mismatches between sentence and picture.

5. The more focus features are present in a sentence, the stronger the tendency is for exhaustive interpretation. Hypothesis 5 is motivated by the developmental pattern seen in Hungarian child language: different grammatical features of focus seem to emerge quite independently. Focused constituents are stressed early while the adult-like pattern of preverbal position and post-verbal position of verbal prefixes emerges gradually and much later. From the point of view of recognition, contrastive stress and preverbal position (along with the unstressed verb) together are both accessible and reliable markers of focus, as both are consistently present in focus sentences. However, preverbal position in itself is not a fully reliable cue for focus, as incorporated arguments, such as the object in (9), frequently occupy this position.

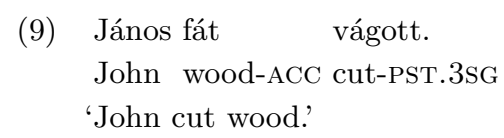

The third cue of focus is the post-verbal position of verbal prefixes which is less accessible (although fully reliable) since prefixes are not always present in sentences. Thus, one might expect differences in the relative importance of these features for the recognition of focus structures.

6. Smaller children between $4-7$ years of age do not show sensitivity to focus, while older children between 8-12 years show some signs of it. This hypothesis is motivated by similar results on focus comprehension in English and Mandarin Chinese presented above showing generally that children approach adult level in the interpretation of lexically and syntactically specified focus after 10 years of age (Gualmini et al. 2003; Costa \& Szendrői 2006; Crain et al. 1994; Philip \& Lynch 2000; Paterson et al. 2005/2006; Notley et al. 2009; Zhou \& Crain 2010). 


\section{Method}

\subsection{Participants}

There were 62 people in three groups participating in the study: a group of adults and two groups of children from different age ranges. Table 2 shows details of the groups. The children were randomly chosen from kindergartens and primary schools in Budapest.

Table 2: Age and number of participants by group

\begin{tabular}{lccc}
\hline & Younger children (YC) & Older children (OC) & Adults (A) \\
\hline Number of participants & 20 & 21 & 21 \\
Mean age (range) & $6 ; 3(4 ; 7-7 ; 10)$ & $10 ; 8(8 ; 0-12 ; 9)$ & $26 ; 6(19 ; 9-51 ; 1)$ \\
\hline
\end{tabular}

All the participants were monolingual with no history of language problems, their hearing and vision was intact, and they were not informed about the aims of the study. None of the adults were educated in linguistics.

\subsection{Procedure and scoring}

Participants completed a sentence-picture verification task. The experimental material consisted of six different sentence types and four different image contexts, each of them depicted in five different scenarios. This arrangement yielded 120 sentence-picture pairs altogether. Sentence types are shown in table 3 , while picture settings are illustrated in figure 1 showing all six sentences and four pictures belonging to Scene 1 ("the deer and the cat"), respectively.

The construction of these sentence types was along the following lines. The main sentence types are (a) neutral SVO, (c) SVO subject focus and (e) SOV object focus. On top of this, in order to investigate the effect of focus features, three other sentence types were included: (b) SVO with object stress, (d) neutral SOV and (f) SOV object focus with verbal prefix. This way four sentence types represent different combinations of the three features marking focus: (b) stress alone, (d) preverbal position alone, (e) stress and preverbal position, (f) stress, preverbal position and postverbal prefix. However, we decided to test the role of these markers only for object focus in order to limit the length of the experiment, making it appropriate for children, too. 
Table 3: Sentence types with examples. Neutral stress is marked by ' and contrastive stress by ".

\begin{tabular}{|c|c|}
\hline Sentence type & Example \\
\hline a. Neutral SVO & $\begin{array}{l}\text { A 'szarvas 'szereli a 'tévét. } \\
\text { the deer fixes the TV-ACC } \\
\text { 'The deer is fixing the TV' }\end{array}$ \\
\hline b. SVO with object stress & $\begin{array}{l}\text { A 'szarvas 'szereli a "tévét. } \\
\text { the deer fixes the TV-ACC } \\
\text { 'It is the TV that the deer is fixing.' }\end{array}$ \\
\hline c. SVO subject focus with verbal prefix & $\begin{array}{l}\text { A "szarvas szereli meg a tévét. } \\
\text { the deer fixes PRT the TV-ACC } \\
\text { 'It is the deer that is fixing the TV.' }\end{array}$ \\
\hline d. Neutral SOV & $\begin{array}{l}\text { A 'szarvas a 'tévét 'szereli. } \\
\text { the deer the TV-ACC fixes } \\
\text { 'The deer is fixing the TV.' }\end{array}$ \\
\hline e. SOV object focus & $\begin{array}{l}\text { A 'szarvas a "tévét szereli. } \\
\text { the deer the TV-ACC fixes } \\
\text { 'It is the TV that the deer is fixing.' }\end{array}$ \\
\hline f. SOV object focus with verbal prefix & $\begin{array}{l}\text { A 'szarvas a "tévét szereli meg. } \\
\text { the deer the TV-ACC fixes PRT } \\
\text { 'It is the TV that the deer is fixing.' }\end{array}$ \\
\hline
\end{tabular}

All pictures featured two animal figures as possible agents performing transitive actions to objects. The four settings were (i) an exhaustive setting with both agents acting on different objects, (ii) a non-exhaustive setting in terms of patients, that is, one of the figures acting on both objects, (iii) a control setting with referential mismatch between sentence and picture, and (iv) a non-exhaustive setting in terms of agents, that is, both figures acting on the same object. Examples are given in figure 1 . All four settings occurred with all of the six sentence types yielding 24 sentence-picture pairs for each of the five scenes. All scenes were similarly constructed to the one depicted in figure 1, with different animals and actions, e.g., a pig and bear watering a tree and a flower, a cow and a rabbit washing a shirt and trousers etc.

The sentence-picture verification task was programmed in E-Prime Professional. All 120 sentence-picture pairs were presented randomly for each person. As the main goal was to test the syntactic-semantic operator hypothesis, the task was constructed without discourse context or any 

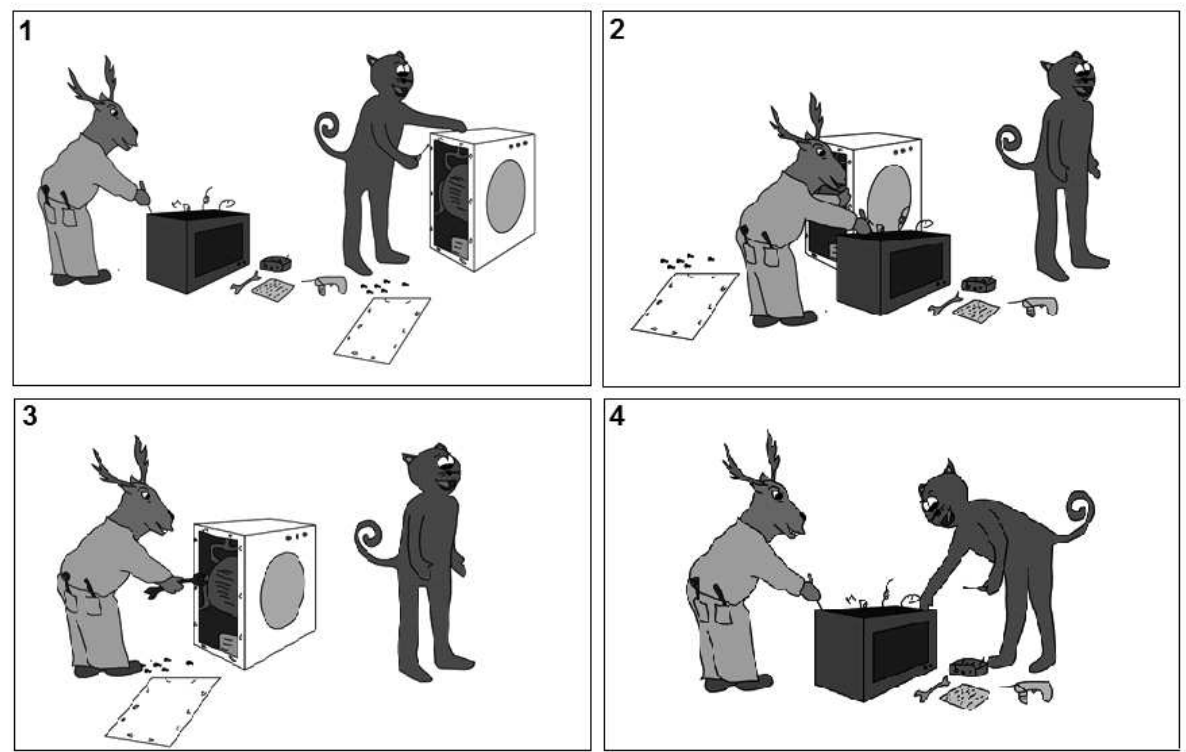

Figure 1: Illustration of the four picture settings. Setting 1: Exhaustive setting with both agents acting on different objects, Setting 2: non-exhaustive object setting, one of the figures acting on both objects, Setting 3 : control setting with referential mismatch between sentence and picture, Setting 4: non-exhaustive subject setting, both figures acting on the same object.

other kinds of pragmatic support. Participants were asked to judge whether the sentence they heard from the loudspeaker was true or not for the picture presented simultaneously on the screen by pressing either of two keys on the keyboard. We expected that participants would accept all the sentences for the exhaustive Setting 1 and none of them for Setting 3 with referential mismatch as there was always a mismatch between the object of the sentence and the depicted object, e.g., tévé 'television' in the sentence and a washing machine in the picture. According to our hypotheses, focus sensitivity would be apparent by the rejection of object focus sentences for pictures with an agent performing an action with two objects (Setting 2), or the rejection of subject focus sentences for pictures two agents performing the same action (Setting 4). Yes/no responses were registered for all items. We evaluated the number of 'yes' responses as acceptance rates for each type of sentence-picture pairs. 


\section{Results}

\subsection{General results}

Firstly, a repeated-measures ANOVA was conducted with Age Group as a between-subjects factor and Setting (exhaustive, two agents, two patients, referential mismatch) and Sentence type (neutral SVO, SVO with object stress, SVO subject focus, neutral SOV, SOV object focus, SOV object focus with prefix) as within-subjects factors. This analysis did not show significant effect of Age group $\left(F(2,59)=0.430, \eta^{2}=0.014\right.$, n.s.) or Sentence type $\left(F(5,55)=2.285, \eta^{2}=0.172\right.$, n.s.), while Setting $\left(F(3,57)=395.814, \eta^{2}=0.954, p<0.001\right)$ had a significant main effect. A significant interaction between Sentence type and Setting $(F(15,45)=$ $\left.3.996, \eta^{2}=0.571, p<0.001\right)$ was observed, and there was also a significant triple interaction between Age group, Sentence type and Setting $\left(F(30,92)=1.669, \eta^{2}=0.352, p<0.05\right)$ revealing a different pattern of performance by the adult group compared to both groups of children. Table 4 shows acceptance rates in percentages for picture-sentence pairs by group.

To look for more specific patterns behind interaction, we also analysed performance separately by Setting and by group. We conducted repeated-measures ANOVAs for each picture setting for each group in order to compare acceptance rates for the sentence types in each setting and group. All these ANOVAs were conducted with Sentence type (neutral SVO, SVO with object stress, SVO subject focus, neutral SOV, SOV object focus, SOV object focus with prefix) as a within-subjects factor. We report the relevant pairwise comparisons of sentence types for each picture.

\subsection{Acceptance of sentences for the exhaustive setting}

The repeated-measures ANOVA conducted on the number of 'yes' responses for pictures with an exhaustive event (Setting 1 in figure 1) revealed no effect of Sentence type in either group (for the younger children: $F(5,15)=1.047, \eta^{2}=0.259$, n.s., for the older children: $F(5,16)=0.593$, $\eta^{2}=0.156$, n.s. for adults: $F(5,16)=0.339, \eta^{2}=0.096$, n.s.). As it is apparent in figure 2, all three groups accepted neutral and various focus sentences for exhaustive contexts to a similarly high degree. 
Table 4: Acceptance rates in percentages for picture-sentence pairs by group (YC: younger children, OC: older children, A: adults)

\begin{tabular}{llcccc}
\hline & & \multicolumn{4}{c}{ Picture type } \\
\cline { 3 - 6 } Sentence type & Group & $\begin{array}{c}\text { exhaustive } \\
\text { event (S1) }\end{array}$ & two agents & two objects & $\begin{array}{c}\text { referential } \\
\text { mismatch (S3) }\end{array}$ \\
\hline neutral SVO & YC & 91.0 & 70.0 & 82.0 & 21.0 \\
& OC & 94.3 & 67.6 & 77.1 & 17.1 \\
SVO with object stress & Y & 94.3 & 76.2 & 82.9 & 11.4 \\
& YC & 92.0 & 66.0 & 76.0 & 27.0 \\
SVO subject focus & Y & 93.3 & 72.4 & 81.0 & 17.1 \\
& YC & 94.3 & 77.1 & 75.2 & 7.6 \\
neutral SOV & OC & 93.3 & 57.0 & 75.0 & 25.0 \\
& A & 91.4 & 41.9 & 77.1 & 24.8 \\
& YC & 89.0 & 66.0 & 76.0 & 20.0 \\
SOV object focus & OC & 92.4 & 77.1 & 74.3 & 13.0 \\
& A & 95.2 & 79.0 & 80.0 & 9.5 \\
& YC & 90.0 & 66.0 & 78.0 & 22.0 \\
& OC & 95.2 & 74.3 & 80.0 & 15.2 \\
SOV object focus & A & 93.3 & 80.0 & 64.8 & 10.5 \\
with prefix & YC & 89.0 & 70.0 & 77.0 & 26.0 \\
& OC & 96.2 & 76.2 & 76.2 & 20.0 \\
& A & 95.2 & 69.5 & 67.6 & 8.6 \\
\hline
\end{tabular}

\subsection{Acceptance of sentences for the referential mismatch setting}

The repeated-measures ANOVA conducted on the number of 'yes' responses for referential mismatch pictures (Setting 3 in figure 1) revealed no effect of Sentence type in either group (for the younger children: $F(5,15)=$ $1.079, \eta^{2}=0.265$, n.s., for the older children: $F(5,16)=1.764, \eta^{2}=0.355$, n.s. for adults: $F(5,16)=1.904, \eta^{2}=0.373$, n.s.). As it can be seen in figure 3 , all three groups accepted neutral and various focus sentences for pictures that featured an object-mismatch to a similarly low degree.

Figures 2 and 3 also show that children's understanding of the experimental task is comparable to adults' as marked by similar percentages of expected and non-expected responses. It is noteworthy that object focus did not seem to improve the detection of referential object mismatches, contrary to previous findings (Birch \& Clifton 1995; Bock \& Mazzella 1983; Cutler \& Fodor 1979). 


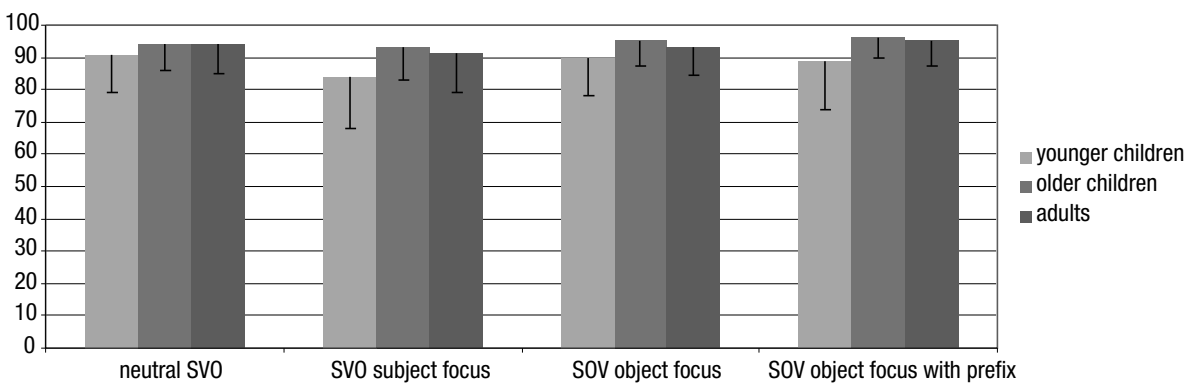

Figure 2: Acceptance rates of neutral and focus sentences for exhaustive events (Setting 1) in percentages

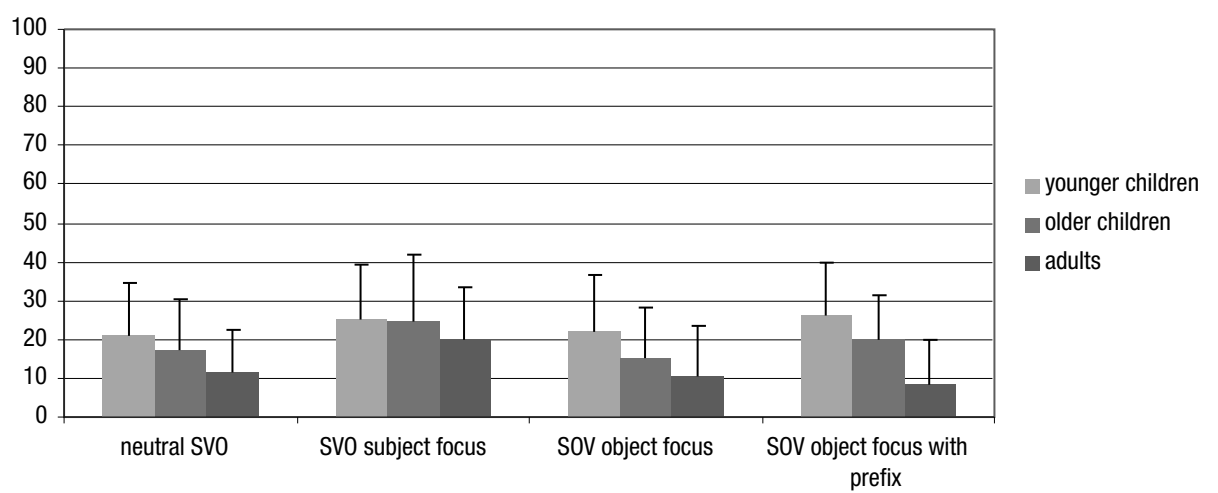

Figure 3: Acceptance rates of neutral and focus sentences for object mismatch pictures (Setting 3) in percentages

\subsection{Acceptance of sentences for the setting with two agents}

The repeated-measures ANOVA conducted on the number of 'yes' responses for pictures depicting an event with two agents acting on the same object (Setting 4 in figure 1) showed a significant effect of Sentence type in the group of adults and the older children (for the younger children: $F(5,15)=1.002, \eta^{2}=0.250$, n.s., for the older children: $F(5,16)=3.564$, $\eta^{2}=0.527, p<0.05$, for adults: $\left.F(5,16)=6.873, \eta^{2}=0.682, p<0.01\right)$. Bonferroni-corrected pairwise comparisons showed different patterns in the groups of adults and older children. According to our hypotheses, sensitivity to subject focus would be apparent by rejection of subject focus sentences for pictures featuring two agents performing the same action. In the adult group, pairwise comparisons supported this expectation showing a significant decrease in the acceptance rate of subject focus compared to neutral SVO sentences $(p<0.01)$ (figure 4$)$. 


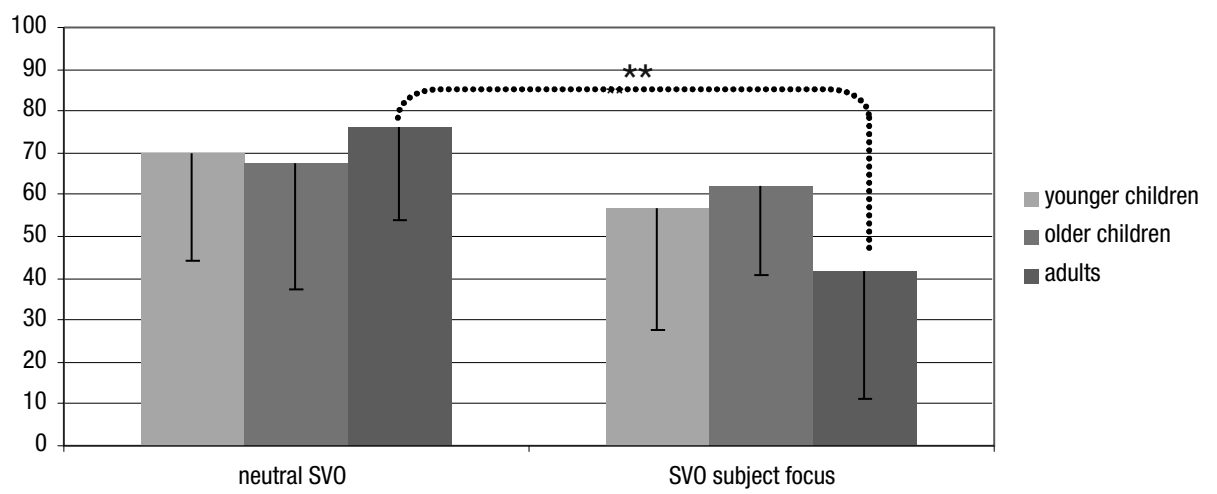

Figure 4: Acceptance rates of neutral and subject focus sentences for pictures with two agents performing the same action (Setting 4 ) in percentages $(*: p<0.05, * *: p<0.01, * * *: p<0.001)$

Although the lower acceptance rate of subject focus compared to neutral SVO sentences for pictures with two agents is present as a tendency in both groups of children, it is not confirmed by statistically significant differences in either. Contrary to our expectations, the performance of older children revealed a single difference between the acceptance of object focus and subject focus sentences preferring the former $(p<0.05)$, but the expected difference between subject focus and neutral SVO sentences could not be seen, so subject focus sensitivity could only be observed in adults.

\subsection{Acceptance of sentences for the setting with two patients}

The repeated-measures ANOVA conducted on the number of 'yes' responses for pictures depicting an agent performing parallel actions with two objects (Setting 2 in figure 1) revealed a significant effect of Sentence type only in the adult group (for the younger children: $F(5,15)=0.516$, $\eta^{2}=0.147$, n.s., for the older children: $F(5,16)=0.455, \eta^{2}=0.125$, n.s., for adults: $\left.F(5,16)=3.540, \eta^{2}=0.525, p<0.05\right)$. Bonferroni-corrected pairwise comparisons showed that adults accepted both types of object focus sentences to a smaller degree than neutral SVO sentences, which is the pattern expected in the presence of object focus sensitivity (figure 5). This pattern was not observed in the performance of either group of children, indicating insensitivity to object focus in the present experimental setting.

As for the independent effect of grammatical markers of focus, according to the same analysis, in itself neither object stress (SVO with object 


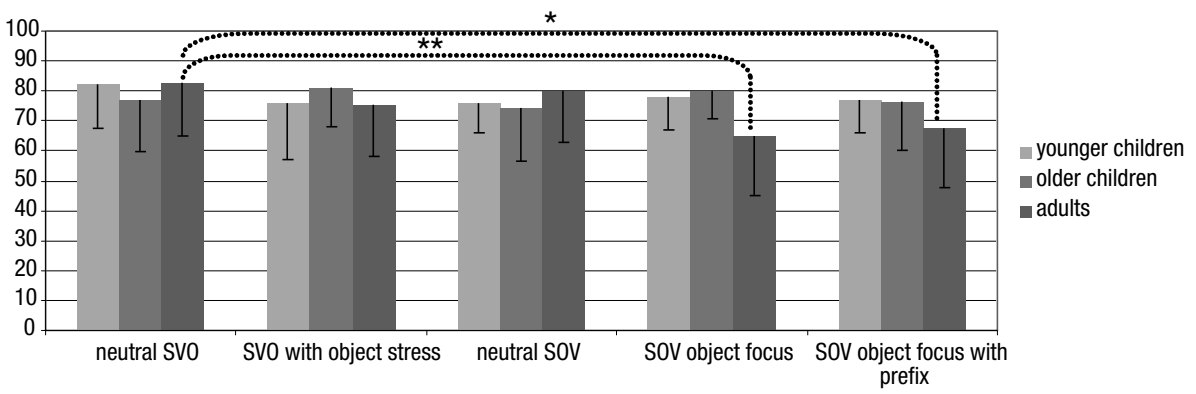

Figure 5: Acceptance rates of neutral and object focus sentences for pictures with the same agent acting with two objects (Setting 2 ) in percentages $(*: p<0.05, * *: p<0.01, * * *: p<0.001)$

stress) nor preverbal position (neutral SOV) was sufficient to trigger exhaustive interpretation as shown by their relatively high acceptance rates, which were similar to those of neutral SVO sentences. On the other hand, the presence of a verbal prefix after the verb did not help adult participants to identify object focus better as shown by similar acceptance rates for object focus sentences with and without verbal prefix. However, these patterns were only observable in the adult group as groups of children did not show any sign of sensitivity to focus in the present experiment.

\subsection{Comparisons between different settings}

To analyse the adult data (the only group showing focus sensitivity) further, the similarity in rejection rates due to non-exhaustive context or referential mismatch was tested with paired-samples t-tests on acceptance rates for subject and object focus sentences in their corresponding non-exhaustive versus the referential mismatch settings. This analysis revealed significant differences in all of the comparisons $(t(20)=10.459, p<0.001$ for object focus sentences and $t(20)=-2.368, p<0.05$ for subject focus sentences), that is, focus sentences were rejected to a higher (or accepted to a smaller) degree in the referential mismatch context than in their appropriate non-exhaustive context (figure 6).

It is also apparent in figure 6 that participants showed a higher sensitivity to subject than to object focus as revealed by another paired-samples t-test comparing acceptance rates for subject and object focus sentences in their appropriate non-exhaustive contexts $(t(20)=3.508, p<0.01)$. 


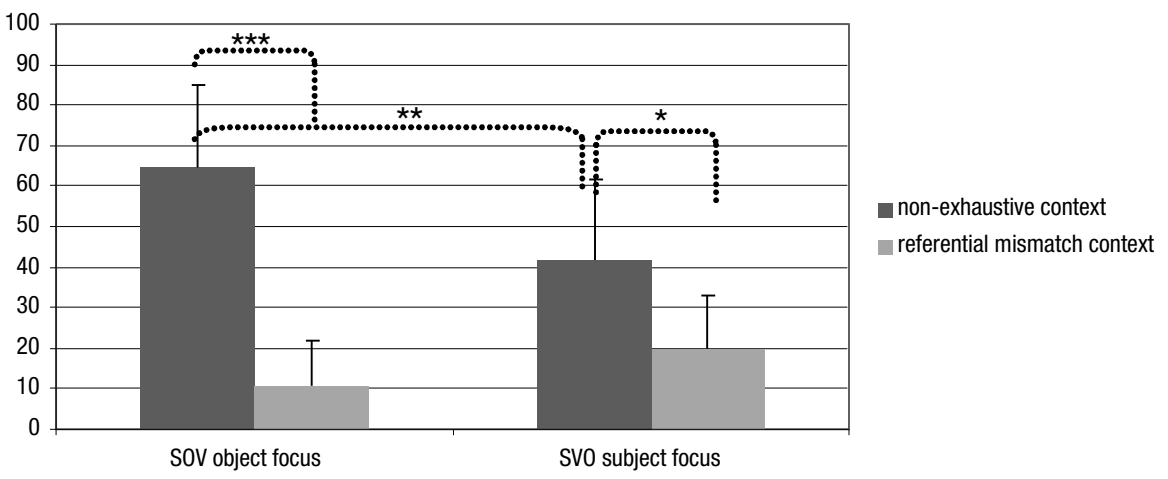

Figure 6: Acceptance rates of focus sentences in non-exhaustive and referential mismatch contexts in percentages $(*: p<0.05, * *: p<0.01, * * *$ : $p<0.001)$

\subsection{Individual variation}

Beyond analysing the data in groups, we also looked at individual variation. Participants showed considerably higher variability when they judged sentences with the pictures with non-exhaustive contexts (Settings 2 and 4) than with exhaustive ones or with referential mismatch pictures (Settings 1 and 3). From a theoretical point of view, intra-individual variation is also interesting: it can be informative to see whether participants are inconsistent in their judgments. To gather data on this particular question, individual responses for neutral and subject focus sentences with the non-exhaustive Setting 4 with two agents were considered. We divided participants into two groups based on their consistency in responding. General error level was estimated to be $\sim 20 \%$ considering acceptance rates for Setting 1 and 3 (figures 2 and 3), participants producing $80 \%$ or more uniform responses to a type of sentence-picture pair were included in the 'consistent' group. We also defined another measure to express consistency of discrimination between sentence types in a certain context. Participants whose responses to neutral and subject focus sentences differed at least by $60 \%$ were considered to consistently discriminate between neutral and focus sentences. Table 5 shows the number of participants satisfying the criteria of consistency for neutral and subject focus sentences in Setting 4 (columns 'Neutral' and 'Subject focus') and consistency of discrimination between them (column 'Neutral-subject focus discrimination') by group. 
Contrary to our expectations, consistency has also been found in erroneous responses as some participants consistently produced non-expected responses, that is, they accepted subject focus sentences or rejected neutral sentences with Setting 4 pictures. In order to distinguish them from those who produced expected and consistent responses, the numbers of participants are shown in expected and non-expected categories for each sentence type.

Table 5: Number of participants responding consistently to neutral and subject focus sentence types in Setting 4 and discriminating them by group (YC: younger children, OC: older children, A: adults)

\begin{tabular}{llccc}
\hline & Group & Neutral & Subject focus & $\begin{array}{c}\text { Neutral-subject focus } \\
\text { discrimination }\end{array}$ \\
\hline expected & YC & 12 & 5 & 3 \\
& OC & 11 & 4 & 1 \\
& A & 14 & 11 & 6 \\
non-expected & YC & 3 & 8 & 0 \\
& OC & 4 & 9 & 0 \\
& A & 1 & 5 & 0 \\
\hline
\end{tabular}

As is apparent from the data in table 4, 60, 52.3 and $66.6 \%$ of younger and older children and adults, respectively, accepted neutral sentences, while only 25,19 and $52.3 \%$ of them rejected subject focus sentences consistently, with the rest of all groups responding inconsistently. This means that there is a great intra-individual inconsistency in the exhaustive interpretation of focus sentences even in adult speakers. The number of participants consistently discriminating neutral and subject focus sentences is even smaller: only 4 out of 41 children and 6 out of 21 adults.

\section{Summary and discussion}

The experiment presented in the paper sought to explore exhaustive interpretation of focus sentences in Hungarian. Children in two age groups and adults participated in a picture-sentence verification task with various sentence and context types. Adults showed a marked sensitivity to focus, revealed by significantly lower acceptance rates of focus than neutral sentences in non-exhaustive contexts, although the acceptance rates for focus sentences were still relatively high. On the other hand, neither group of children showed any sign of focus sensitivity as a group - for this 
reason, further specific analyses of sensitivity patterns were based on the adult data only. Acceptance of focus sentences was significantly lower for contexts with referential mismatch than for non-exhaustive contexts. Differences between the sensitivity to subject and object focus were revealed by lower acceptance rates for subject than object focus sentences in their respective non-exhaustive contexts. Both children and adults showed remarkable inconsistency in distinguishing neutral and focus sentences in non-exhaustive contexts. As far as the theory of focus is concerned, although there were clear signs of focus sensitivity in adults, the pattern of our results contradicts the clear dissociative predictions of the syntactic-semantic model suggesting that focus sentences are not semantically exhaustive. These issues will be discussed in the following evaluation of our hypotheses.

First, our basic prediction was that adult speakers accept focus sentences as well as neutral sentences in exhaustive contexts. This hypothesis was supported by the results, as adults' acceptance rates were similarly above $90 \%$ for neutral and focus sentences, providing a firm baseline for comparisons with non-exhaustive contexts (figure 2). Second, the syntactic-semantic operator model predicted that adult speakers do not accept focus sentences but do accept neutral sentences in non-exhaustive contexts. However, this expectation is not completely borne out by the data. Adults' acceptance rates for focus sentences were significantly lower than for neutral sentences in non-exhaustive contexts, but the acceptance rates for focus sentences was still relatively high, at $\sim 40 \%$ and $\sim 65 \%$ for subject and object focus sentences, respectively (figure 4 and 5). This surprisingly high level of acceptance contradicts predictions of the syntactic-semantic operator model since a semantically determined focus feature would predispose participants to reject focus sentences in non-exhaustive contexts systematically, with only occasional errors. The analysis of individual variation also showed that a distinction between neutral and focus sentences is not evident in most of the adults, let alone children, as almost threequarters of the adults were classified as being inconsistent in that respect.

The third hypothesis concerned the relative levels of subject and object focus sensitivity. The difference between subject and object focus sensitivity revealed by the results (figure 6 ) is also in conflict with predictions of the syntactic-semantic operator model: such a difference can hardly be accounted for by semantic features, since a formal focus feature should work equally well for subjects and objects. As argued in the introduction, the differences in frequency of occurrence of preverbal subjects versus preverbal objects might account for this pattern of performance. If objects 
occur more frequently in preverbal position than subjects in neutral sentences, they might be more difficult to recognize as being focused in the same position, explaining lower sensitivity for object focus. This result, however, has to be handled with care, as it could be an artefact of the properties of the picture stimuli. Two agents performing the same action (the non-exhaustive context for subject focus sentences) might be more salient perceptually than one agent acting on two objects (the non-exhaustive context for object focus sentences), making the recognition of an exhaustivity mismatch easier for subject focus sentences.

Fourth, the assumption that acceptance rates for focus sentences in non-exhaustive contexts might be comparable to those for other types of semantic anomalies such as referential mismatches was not supported by the results, as adults accepted subject and object focus sentences with referential mismatch pictures at a significantly lower $\sim 20 \%$ and $\sim 10 \%$ rate, respectively, than with their non-exhaustive pictures (figure 6). In other words, while they quite consistently judged sentences with referential mismatches to be false, they showed a significantly weaker tendency to reject violations of exhaustivity, accepting $\sim 40 \%$ and $\sim 60 \%$ of subject and object focus sentences, respectively, referring to non-exhaustive events. This pattern suggests that speakers treated semantic anomalies of the propositional content and violations of exhaustivity differently.

As for the role of different focus features, it was assumed that the more focus features are present in a sentence, the stronger the tendency is for its exhaustive interpretation. Results showed that adults do not consider either preverbal position or contrastive stress alone as a marker of focus. However, when both markers were present, significantly lower acceptance rates for non-exhaustive contexts indicated the recognition of focus. The additional presence of a verbal prefix after the verb, however, did not increase focus sensitivity further (figure 5). It seems that preverbal position and contrastive stress together are the markers people mostly rely in focus recognition. These conclusions are limited in their scope, however, due to shortcomings in our experimental design. The relative role of focus markers was only studied in object focus sentences, where differences in acceptance rates were generally smaller than those for subject focus.

Although research on focus sensitivity in English and Mandarin Chinese suggested that children around 10 are able to compute alternative sets and interpret focus sentences exhaustively, our results did not indicate the presence of such ability in children as a group. We attribute this difference in the findings to an essential difference between the linguistic structures under investigation in Hungarian and the other languages. 
In the English and Chinese studies, focus was lexically marked with the particle only (and its equivalents in Chinese) while in Hungarian it was only structurally marked. Structural markers are perceptually less salient than lexical ones, and this asymmetry in itself might account for the lack of focus sensitivity of children in our results. Future research should determine whether Hungarian children also interpret sentences with lexical particles exhaustively. Interestingly, despite the lack of focus sensitivity at the group level, analysis of individual data showed that the consistent pattern of discrimination between neutral and focus sentences is indeed present in some children as well, even in the younger group. This suggests that there are huge individual differences in the development of exhaustive interpretation of focus sentences which might be influenced by non-semantic factors.

To conclude, although there were clear signs of focus sensitivity in adults as a group, the relatively high acceptance rates for focus sentences in non-exhaustive contexts, the difference between the acceptance of referential mismatches and violations of exhaustivity, the difference between sensitivity for subject and object focus and the remarkable inconsistency of adults clearly contradict the present form of the syntactic-semantic operator model and suggest that focus sentences are not interpreted exhaustively in semantic terms. These patterns might be considered to be more compatible with theories emphasizing factors other than pure formal semantics. The semantic presupposition and pragmatic implicature hypotheses are lending themselves as possible candidates, since both are concerned with the role of context and the latter with listeners' inferences. However, it is far from obvious how the results of this experiment could be accounted for by either theory. Semantic presupposition theory predicts that speakers might neither clearly accept nor reject focus sentences in non-exhaustive contexts on account of the violation of the presupposition. Since a false presupposition does not result in a false statement, participants might hesitate between true or false responses, as the task did not offer other alternative responses. Pragmatic implicature theory predicts individual variation and less distinction between neutral and focus sentences due to context-related inferences; predictions based on this model could not be made in the present experiment lacking variables of discourse context. Consequently, although both semantic presupposition and pragmatic implicature theories seem to be promising alternatives to the syntactic-semantic operator model, the present experimental design is not suitable for testing these theories. Models concerned with situational context and pragmatic principles have to be tested in discourse contexts that allow precise 
control of different implications and presuppositions and record responses in a more fine-grained way. Clarification of predictions by these models is also necessary: their explanatory strength depends on various extralinguistic factors that have to be identified and whose role has to be specified. Future research should explore these theoretical possibilities with studies that control contextual factors of sentence processing.

\section{References}

Babarczy, Anna. 2006. Negation and word order in Hungarian child language. Lingua 116. 377-392.

Birch, Stacy and Charles Clifton. 1995. Focus, accent, and argument structure: Effects on language comprehension. Language and Speech 38. 365-391.

Bock, J. Kathryn and Joanne R. Mazzella. 1983. Intonational marking of given and new information: Some consequences for comprehension. Memory \& Cognition 11. 64-76.

Brody, Michael. 1990. Remarks on the order of elements in the Hungarian focus field. In I. Kenesei (ed.) Approaches to Hungarian 3: Structures and arguments. Szeged: JATE. 95-121.

Brody, Michael. 1995. Focus and Checking Theory. In I. Kenesei (ed.) Approaches to Hungarian 5: Levels and structures. Szeged: JATEPress. 29-43.

Chomsky, Noam. 1971. Problems of knowledge and freedom. New York: Pantheon.

Costa, João and Kriszta Szendrői. 2006. Acquisition of focus marking in European Portuguese. In V. Torrens and L. Escobar (eds.) The acquisition of syntax in Romance languages. Amsterdam \& Philadelphia: John Benjamins. 319-330.

Crain, Stephen, Weija Ni and Laura Conway. 1994. Learning, parsing and modularity. In C. Clifton, L. Frazier and K. Rayner (eds.) Perspectives on sentence processing. Hillsdale, NJ: Lawrence Erlbaum. 443-467.

Crain, Stephen and Rosalind Thornton. 1998. Investigations in Universal Grammar: A guide to experiments on the acquisition of syntax and semantics. Cambridge MA: MIT Press.

Cutler, Anne and Jerry A. Fodor. 1979. Semantic focus and sentence comprehension. Cognition 7. 49-59.

É. Kiss, Katalin. 1998. Identificational focus versus information focus. Language 74. $245-273$.

É. Kiss, Katalin. 2002. The syntax of Hungarian. Cambridge: Cambridge University Press.

É. Kiss, Katalin. 2006a. Focussing as predication. In Molnár \& Winkler (2006, 169-193).

É. Kiss, Katalin. 2006b. Érvek és ellenérvek a fókusz [+kimerítő] jegyével kapcsolatban [Arguments and counterarguments regarding the [+exhaustive] feature of the focus]. In L. Kálmán (ed.) KB 120: A titkos kötet. Nyelvészeti tanulmányok Bánréti Zoltán és Komlósy András tiszteletére [KB 120: The secret volume. Studies in linguistics in honour of Zoltán Bánréti and András Komlósy]. Budapest: MTA Nyelvtudományi Intézet \& Tinta Könyvkiadó. 37-48.

Acta Linguistica Hungarica 60, 2013 
É. Kiss, Katalin. 2008a. The structure of the Hungarian VP revisited. In C. Piñón and Sz. Szentgyörgyi (eds.) Approaches to Hungarian 10: Papers from the Veszprém conference. Budapest: Akadémiai Kiadó. 31-58.

É. Kiss, Katalin. 2008b. Topic and focus: Two structural positions associated with logical functions in the left periphery of the Hungarian sentence. Acta Linguistica Hungarica 55. 287-296.

É. Kiss, Katalin. 2011. Szerkezetileg kódolt előfeltevés a magyar mondatszerkezetben [Structurally coded presupposition in Hungarian sentence structure]. Általános Nyelvészeti Tanulmányok 23. 245-264.

Farkas, Donka. 1986. The syntactic position of focus in Hungarian. Natural Language and Linguistic Theory 4. 77-96.

Filik, Ruth, Kevin B. Paterson and Simon P. Liversedge. 2009. The influence of only and even on on-line semantic interpretation. Psychonomic Bulletin \& Review 16. $678-683$.

Gergely, György. 1988. The effect of focus-based inferences on word recognition. Hungarian Psychological Review 28. 443-471.

Gergely, György. 1991. Free word order and discourse interpretation: Experimental studies on hungarian sentence processing. Budapest: Akadémiai Kiadó.

Gualmini, Andrea, Simona Maciukaite and Stephen Crain. 2003. Children's insensitivity to contrastive stress in sentences with only. In Proceedings of the 25th Annual Penn Linguistics Colloquium. Philadelphia: University of Pennsylvania Press. 87-110.

Kálmán, László and Noor van Leusen. 1993. The semantics of free focus. ILLC: Amsterdam.

Kenesei, István. 2005. Hungarian in focus (Review article). Journal of Linguistics 41. 409-35.

Kenesei, István. 2006. Focus as identification. In Molnár \& Winkler (2006, 137-168).

Kenesei, István. 2009. Quantifiers, negation, and focus on the left periphery in Hungarian. Lingua 119. 564-591.

Liversedge, Simon P., Kevin B. Paterson and Emma Clayes. 2002. The influence of 'only' on syntactic processing of 'long' reduced relative clause sentences. Quarterly Journal of Experimental Psychology 55A. 225-241.

Malt, Barbara. 1985. The role of discourse structure in understanding anaphora. Journal of Memory and Language 24. 271-289.

Molnár, Valéria and Susanne Winkler (eds.). 2006. The architecture of focus (Studies in Generative Syntax 82). Berlin \& New York: Mouton de Gruyter.

Notley, Anna, Peng Zhou, Stephen Crain and Rosalind Thornton. 2009. Children's interpretation of focus expressions in English and Mandarin. Language Acquisition 16. $240-282$.

Onea, Edgar. 2007. Exhaustivity, focus and incorporation in Hungarian. In M. Aloni, P. Dekker and F. Roelofsen (eds.) Proceedings of the 16th Amsterdam Colloquium. Amsterdam: ILLC. 169-74.

Onea, Edgar. 2009. Exhaustiveness of Hungarian focus. Experimental evidence from Hungarian and German. In A. Riester and E. Onea (eds.) Focus at the syntaxsemantics interface. Stuttgart: University of Stuttgart. 53-68. 
Onea, Edgar and David Beaver. 2011. Hungarian focus is not exhausted. In S. Ito and E. Cormany (eds.) Semantics and Linguistic Theory (SALT) 19. Ithaca, NY: CLC Publications. 342-359.

Paterson, Kevin B., Simon P. Liversedge and Geoffrey Underwood. 1999. The influence of focus operators on syntactic processing of focus operators on syntactic processing of 'short' reduced relative clause sentences. Quarterly Journal of Experimental Psychology 52A. 717-737.

Paterson, Kevin B., Simon P. Liversedge, Diane White, Ruth Filik and Kristina Jaz. 2005/2006. Children's interpretation of ambiguous focus in sentences with "only". Language Acquisition 13. 253-284.

Philip, William and Emily Lynch. 2000. Felicity, relevance, and acquisition of the grammar of every and only. In C. S. Howell, S. A. Fish and T. Keith-Lucas (eds.) Proceedings of the 24th Annual Boston University Conference on Language Development. Somerville, MA: Cascadilla Press. 583-596.

Pléh, Csaba. 1998. A mondatmegértés a magyar nyelvben [Sentence interpretation in Hungarian]. Budapest: Osiris Kiadó.

Pléh, Csaba and Balázs Sinkovics. 2011. Word order and focusing effects in the memory representation of Hungarian sentences. Acta Linguistica Hungarica 58. 120-133.

Reinhart, Tanya. 1995. Interface strategies (OTS Working Papers in Theoretical Linguistics). Utrecht: OTS.

Selkirk, Elisabeth O. 1984. Phonology and syntax. The relation between sound and structure. Cambridge MA: MIT Press.

Skopeteas, Stavros and Gisbert Fanselow. 2010. Focus types and argument asymmetries: A cross-linguistic study in language production. In C. Breul and E. Göbbel (eds.) Contrastive information structure. Amsterdam \& Philadelphia: John Benjamins. 169-197.

Sperber, Dan and Deirdre Wilson. 1995. Relevance: Communication and cognition. Second edition. Cambridge MA \& Oxford: Blackwell.

Szabolcsi, Anna. 1981. Compositionality in focus. Folia Linguistica 15. 141-161.

Szendröi, Kriszta. 2003. A stress-based approach to the syntax of Hungarian focus. The Linguistic Review 20. 37-78.

Szendröi, Kriszta. 2004. Focus and the interaction between syntax and pragmatics Introduction. Lingua 114. 229-254.

Tóth, Ildikó. 2008. Az ige-igekötő szórend elsajátítási folyamata a gyereknyelvben [The acquisition of the verb-verbal prefix word order in child language]. Nyelvtudományi Közlemények 105. 218-242.

Wedgwood, Daniel. 2003. Predication and information structure: A dynamic account of Hungarian pre-verbal syntax. Doctoral dissertation. University of Edinburgh.

Wedgwood, Daniel. 2005. Shifting the focus. From static structures to the dynamics of interpretation. Amsterdam: Elsevier.

Wedgwood, Daniel, Gergely Pethő and Ronnie Cann. 2006. Hungarian 'focus position' and English it-clefts: Semantic underspecification of 'focus' readings. Ms. University of Edinburgh.

Zhou, Peng and Stephen Crain. 2010. Focus identification in child Mandarin. Journal of Child Language 37. 965-1005. 